\title{
A NEW SPECIES OF STYRAX SERIES CYRTA (STYRACACEAE) FROM CAMBODIA
}

\author{
Peter W. Fritsch \\ Botanical Research Institute of Texas \\ 1700 University Drive \\ Fort Worth, Texas 76107, U.S.A. \\ pfritsch@brit.org
}

\author{
Philip Thomas \\ Royal Botanic Garden Edinburgh \\ 20 Inverleith Row \\ Edinburgh EH3 5LR \\ Scotland, U.K. \\ pthomas@rbge.org.uk
}

\author{
Viboth Ly \\ Department of Biology \\ Royal University of Phnom Penh \\ Russian Federation Boulevard \\ Toul Kork, Phnom Penh, CAMBODIA \\ vibothly@yahoo.fr
}

ABSTRACT

\begin{abstract}
Styrax cambodianus, a new species of Styrax L. ser. Cyrta (Lour.) P.W. Fritsch from Virachay National Park in northeastern Cambodia, is described and illustrated. It is similar to S. hookeri C.B. Clarke but differs by its two most proximal leaves alternate, abaxial surfaces with mostly planar or occasionally slightly raised quaternary veins, rotate corollas, and stamen filaments strongly flexuous in the upper half. Styrax cambodianus is known only from the type and is the only species of the series unequivocally documented from Cambodia. The discovery of this species brings the number of Styrax ser. Cyrta to 31.
\end{abstract}

KeY Words: Cambodia, endemic, new species, Styrax

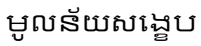

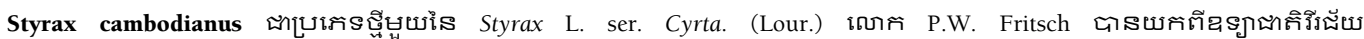

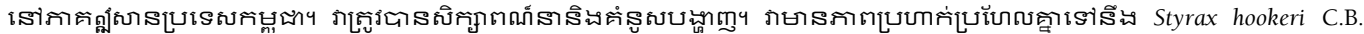

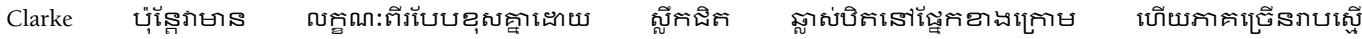

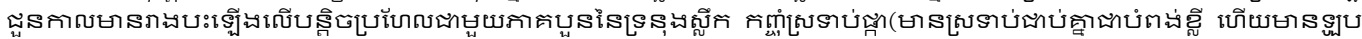

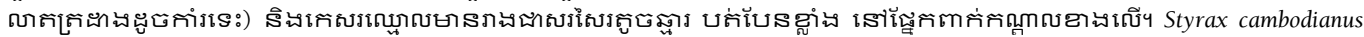

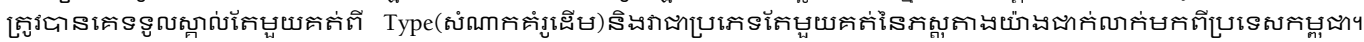

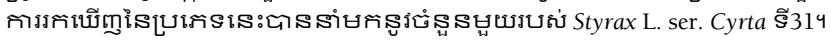

\section{INTRODUCTION}

Styrax [sect. Styrax] ser. Cyrta (Lour.) P.W. Fritsch (Styracaceae) comprises 30 species from East and Southeast Asia and adjacent islands, and North America (Huang et al. 2003; Zhou et al. 2015; Li \& Fritsch 2018; Xu et al. in press). The series is defined by glandular-serrate leaf blade margins and inflorescences produced laterally (as well as terminally) on at least some shoots (Fritsch 1999). The taxonomy of the series was revised in separate accounts treating the members of the series with imbricate and valvate corolla aestivation, respectively (Huang et al. 2003; Li \& Fritsch 2018). These accounts treated the 28 species of Styrax ser. Cyrta known at the time (24 from Asia and four from North America). Since these were published, an additional two Chinese endemic species new to science have been discovered (Zhou et al. 2015; Xu et al. in press).

During field exploration of Virachay National Park, Ratanikiri Province, Cambodia, the second author encountered flowering individuals of Styrax with an unusual combination of characters, a specimen of which was sent to the first author for identification. On careful examination of this material and in consultation with relevant taxonomic literature (Huang et al. 2003), we confirmed that it represents a species of Styrax new to science. The new species is described and illustrated here.

\section{TAXONOMIC TREATMENT}

Styrax cambodianus P.W. Fritsch, sp. nov. (Figs. 1, 2). TyPE: CAMBODIA. Ratanikiri Province: Virachay National Park, Teuk Chrus Bei Chon (Three Steps Waterfall), O'Tayak River above main camp, Indian Thailand 48 P: 756286: 1583438, 336-549 m, 16 Dec 2005, P. Thomas, K. Theah, T. Sokhon, S. Teng, S. Sokhon, \& Y. Bounsoeung 75 (holotyPE: RUPP!; IsotyPEs: BRIT!, E!, L!, P!, $\mathrm{TCD} !)$.

Haec species Styraci hookeri C.B. Clarke simillima, sed ab eo foliis proximalibus alternis, subtus venis quaternariis maximam partem planis, corollis rotatis, filamentis staminum valde flexuosis differt.

J. Bot. Res. Inst. Texas 14(2): $343-347.2020$

https://doi.org/10.17348/jbrit.v14.i2.1011

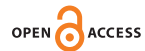




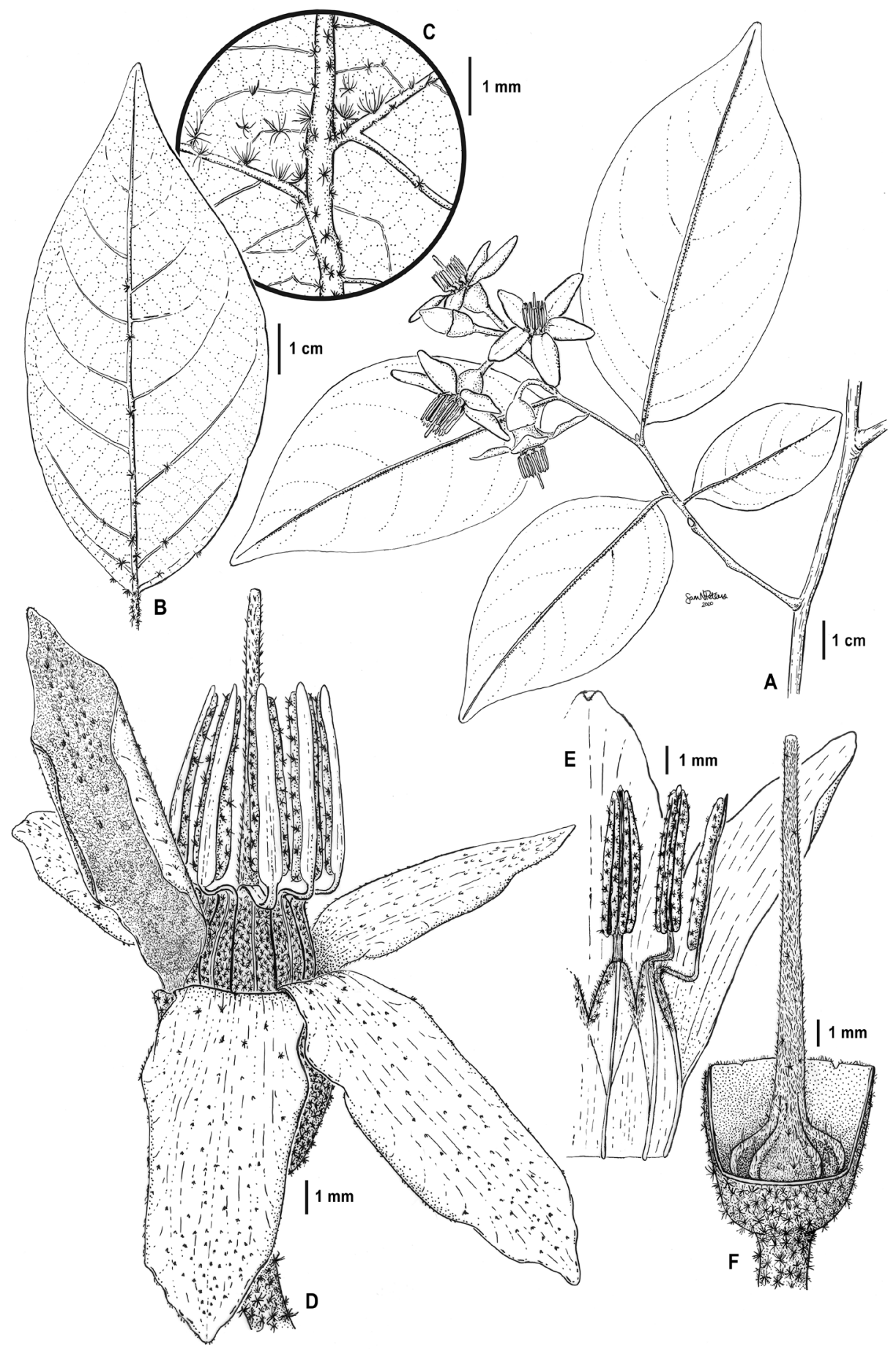

FIG. 1. Styrax cambodianus. A. Flowering branchlet with leaves in abaxial view. B. Leaf, abaxial view. C. Leaf blade, abaxial surface showing midvein and two secondary veins with marsupiform domatia in the axils of the secondary veins. D. Flower with one corolla lobe oriented to show abaxial surface. E. Corolla cut longitudinally to show part of inner surface of corolla and part of androecium. F. Calyx and gynoecium with calyx cut open ventrally to show upper part of ovary. Based on the holotype and BRIT and $E$ isotypes. 


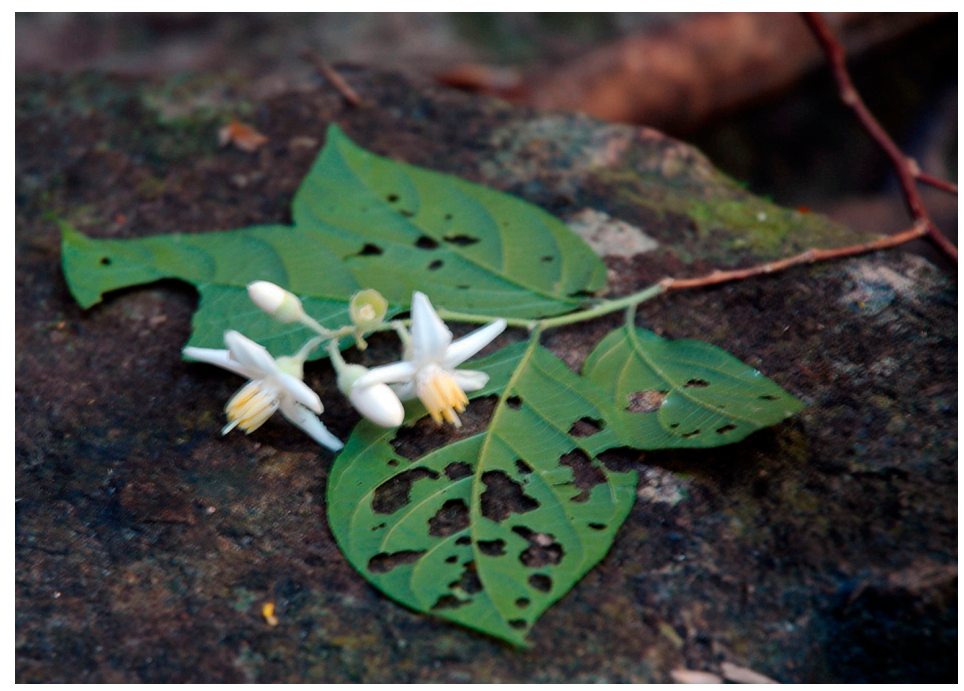

Fig. 2. Flowering branchlet of Styrax cambodianus. Photo by Philip Thomas.

Shrubs or trees, apparently evergreen, to ca. $15 \mathrm{~m}$ tall. Young branchlets brownish green with scattered white to pale yellow stellate trichomes, young fertile branchlets 3- to 5-leaved, 7-12 cm long, 0.8-1.4 mm wide at narrowest point proximally; mature branchlets dark maroon, glabrous. Leaves alternate (including the two most promixal), 4 to 5 per branchlet; petiole rounded abaxially and concave adaxially in cross section, 2.5-5.0 mm long, covered with 7- to 15-armed white to pale yellow stellate trichomes up to $0.7 \mathrm{~mm}$ long, also with several sessile globular golden yellow glands $0.1-0.4 \mathrm{~mm}$ diam. scattered on upper margin; leaf blade ovate, ovate-oblong, or elliptic, $8.5-12.2 \times 4.2-6.4 \mathrm{~cm}$ (it is unknown whether there is a size difference between the leaves of sterile versus fertile shoots, because only the leaves of fertile shoots were available for examination), 1.7-2.4 times as long as wide, membranaceous, both surfaces when dry brownish green with yellow veins, with sparse white to pale yellow stellate trichomes mainly on major veins with arms up to $0.5 \mathrm{~mm}$ long, midvein abaxially prominent, adaxially sulcate, secondary veins 5 to 8 on each side of midvein, abaxially raised with axils of many bearing thin marsupiform domatia ca. $2 \mathrm{~mm}$ wide, adaxially planar to slightly raised, tertiary veins slightly raised, quaternary veins mostly planar, occasionally slightly raised, base broadly cuneate to subrounded, margin appearing entire but with regularly spaced minute (up to $0.20 \mathrm{~mm}$ long) glands, apex acute to acuminate. Inflorescences pseudoterminal and occasionally lateral; lateral inflorescences absent or 1-flowered; pseudoterminal inflorescences raceme-like, rather congested, 2.5-4.0 cm long, 2- to 4-flowered, peduncle and rachis greenish brown, with white to pale yellow stellate trichomes. Pedicels 4.5-7.2 × 1.1-1.3 $\mathrm{mm}$, covered with white to pale yellow stellate trichomes; bracteoles caducous, borne from base to middle of pedicel, linear-subulate, $0.5-4.0 \mathrm{~mm}$ long. Flowers $1.8-2.0 \mathrm{~cm}$ long. Calyx broadly cupuliform, 5.2-5.5 × 7.0$8.0 \mathrm{~mm}$, abaxially covered with white to pale yellow stellate trichomes with arms up to $0.5 \mathrm{~mm}$ long becoming less dense within $1 \mathrm{~mm}$ of margin, adaxially light brown and sparsely appressed-stellate-pubescent throughout, margin brownish green, chartaceous, essentially truncate, eglandular. Corolla with imbricate aestivation, white, rotate (but bearing a short tube), $1.7-1.9 \mathrm{~cm}$ long; tube $4.0-4.5 \mathrm{~mm}$ long, abaxially glabrous proximally, pubescent distally; lobes 5, elliptic-lanceolate or -oblong, 13-14 × 5.5-7.0 mm, membranaceous, abaxially covered with white to pale yellow appressed stellate trichomes, adaxially less densely so, apex acute to obtuse. Stamens 10; tube ca. $0.6 \mathrm{~mm}$ long, dorsally pubescent, ventrally glabrous; filaments strongly flexuous (abruptly angled outwards at ca. half the length and then upwards at ca. 3/4 length), 5.0-5.5 mm long, 1.3-1.5 mm wide at base tapering to $0.4-0.6 \mathrm{~mm}$ wide at apex, dorsally flattened, ventrally thickened marginally, dorsally 
stellate-pubescent becoming glabrous distally, ventrally stellate-pubescent mainly on margins proximally becoming glabrous distally; anthers 4.8-6.0 mm long, wider than distal portion of filament, connective 0.6$1.0 \mathrm{~mm}$ wide, prolonged $0.4-0.5 \mathrm{~mm}$ beyond thecae, glabrous, thecae with sparse to dense pale yellow trichomes. Free portion of ovary ca. $2.8 \times 2.0 \mathrm{~mm}$, covered with yellow stellate trichomes. Style 13-15 mm long, covered with yellow stellate trichomes nearly to apex; stigma truncate. Fruit unknown.

Distribution, Habitat, Abundance, and Phenology.-Styrax cambodianus is known only from the type collection made in Virachay National Park, northeastern Cambodia. The species was found growing in evergreen secondary forest around a permanently wet watercourse. It was observed to be common in the area, growing among old bamboo stands at the edge of the trails, and was flowering in December with many fallen corollas on the forest floor.

Conservation Assessment.-Because it is only known from the type collection made from a single population, we recommend the category "Data Deficient" (DD) for Styrax cambodianus, in accordance with the International Union for Conservation of Nature Red List criteria (IUCN Standards and Petitions Subcommittee 2019).

Discussion.-With the description of this new species the total number of species in Styrax ser. Cyrta is now increased to 31. Styrax cambodianus is well placed within Styrax sect. Styrax by having corolla buds with their sides convex in outline and membranaceous corolla lobes (Fritsch 1999). Although the species of the section have been described as consistently deciduous (Fritsch 1999), it is now known that at least one of its species (S. glabrescens Benth.) is evergreen in at least part of its range (R. Kriebel, pers. comm.), and so if $S$. cambodianus is indeed evergreen, it would provide another exception to the otherwise deciduous condition of the species in the section. Moreover, although it does not have bases of young shoots with stalked ferrugineous stellate trichomes distinct from the rest of the vestiture as in the rest of the section (Fritsch 1999), the globular golden-colored glands observed on the petiole and bases of the leaf blade in the new species may be homologous with such trichomes. The new species can be placed within Styrax [sect. Styrax] ser. Cyrta by its glandularserr(ul)ate leaf blade margins (although in this case the margins appear entire at a distance but have regularly spaced minute linear glands $\leq 0.2 \mathrm{~mm}$ long) and inflorescences produced laterally (as well as terminally) on at least some shoots (Fritsch 1999).

The flowers of the new species appear to be unique in Styrax ser. Cyrta by the combination of their large size, rotate shape (but with a short tube), and strongly flexuous stamen filaments. In the key to the species of the series with imbricate corolla aestivation (Huang et al. 2003:500-502), S. cambodianus keys fairly well to lead 19a, S. hookeri C.B. Clarke, a species distributed from eastern India through Myanmar and southwestern China. Styrax cambodianus is easily distinguished from S. hookeri, however, by its two most proximal leaves alternate (versus subopposite to opposite), abaxial surfaces with mostly planar or occasionally slightly raised quaternary veins (versus prominent), rotate corollas (versus campanulate), and stamen filaments strongly flexuous (versus straight).

The new species is also similar to Styrax chrysocarpus H.L. Li by its yellowish trichomes on the leaf blade and inflorescence rachis. A complete comparison of S. cambodianus to S. chrysocarpus cannot be conducted because S. cambodianus is only known in flower with fruit unknown, whereas S. chrysocarpus is only known in fruit with flower unknown. Nonetheless, S. cambodianus is distinct from S. chrysocarpus vegetatively by its membranaceous (versus chartaceous) leaves with shorter petioles (2.5-5.0 mm long versus 5-8 $\mathrm{mm}$ long) and smaller blades $(8.5-12.2 \times 4.2-6.4 \mathrm{~cm}$ versus $10-20 \times 5.5-11 \mathrm{~cm})$ with sparsely pubescent abaxial surfaces (versus densely pubescent) and slightly raised tertiary veins (versus prominent).

The new species differs from the two other species of Styrax ser. Cyrta with imbricate corolla aestivation published after the treatment of Huang et al. (2003). It differs from S. rhytidocarpus W. Yang \& X.L. Yu (Zhou et al. 2015) by its pubescent inflorescence rachis, bracteoles, and pedicels (versus glabrous) and S. hwangiae M. Tang \& W.B. Xu (Xu et al. in press) by its membranaceous leaf blades that are abaxially sparsely pubescent (versus coriaceous and abaxially tomentose), calyx without long-stalked trichomes (versus with long-stalked 
trichomes) and with minute and indistinct teeth (versus 2-5 mm long), and corolla 1.7-1.9 cm long (versus $1.2-1.5 \mathrm{~cm}$ long).

The new species is also easily distinguished from other species of Styrax whose geographic distributions are close to its location. Styrax curvirostratus (Svengs.) Y.L. Huang \& P.W. Fritsch, a species endemic to southern Vietnam and also with imbricate corolla aestivation, is distinguished by its leaf blades with tertiary and quaternary veins irregularly reticulate and conspicuously raised on both sides (versus tertiary veins slightly raised, quaternary veins mostly planar, occasionally slightly raised) and corolla $0.9-1.2 \mathrm{~cm}$ long (versus 1.7-1.9 cm). Styrax agrestis (Lour.) G. Don, from Laos and Vietnam, and S. finlaysonianus Wall. ex G. Don, from China and Vietnam, are distinguished by their valvate corolla aestivation. Styrax agrestis is further distinguished vegetatively by its leaf blades on fertile shoots $3.7-6.9(-8) \times 1.8-3.5 \mathrm{~cm}$ (versus $8.5-12.2 \times 4.2-6.4 \mathrm{~cm}$ ), and $S$. finlaysonianus by the petiole $7-17 \mathrm{~mm}$ long with stellate trichome arms up to $0.06-0.30 \mathrm{~mm}$ long (versus petiole 2.5-5.0 mm long with stellate trichome arms up to $0.70 \mathrm{~mm}$ long).

Styrax cambodianus is the only known species of Styrax ser. Cyrta collected from Cambodia with certainty. The one possible exception is S. finlaysonianus, the type of which has been cited in various works as probably from Cambodia. However, Li and Fritsch (2018) provide evidence suggesting that it was instead collected in either Thailand or Vietnam.

\section{ACKNOWLEDGMENTS}

We acknowledge the support of the Ministry of Environment and Mr. Meas Sophal from the Biodiversity and Protected Areas Management Project for the field work in December 2005 in Virachay National Park. We thank the rangers, especially Mr. Thon Sokhon, for sharing their knowledge of the national park. Thanks also to Samantha Peters for the illustration, and the helpful comments of three reviewers on the manuscript (Ken Chambers, Gary Li, and Hengchang Wang). The Royal Botanic Garden Edinburgh (RBGE) is supported by the Scottish Government's Rural and Environmental Science and Analytical Services Division.

\section{REFERENCES}

FRITSCH, P.W. 1999. Phylogeny of Styrax based on morphological characters, with implications for biogeography and infrageneric classification. Syst. Bot. 24:355-378. doi:10.2307/2419695

HuAnG, Y., P.W. FritsCH, \& S. SHI. 2003. A revision of the imbricate group of Styrax series Cyrta (Styracaceae) in Asia. Ann. Missouri Bot. Gard. 90:491-553. doi:10.2307/3298541

IUCN Standards and Petitions Subcommittee. 2019. Guidelines for using the IUCN Red List categories and criteria, ver. 14. Available at http://cmsdocs.s3.amazonaws.com/RedListGuidelines.pdf. Accessed Aug 2020.

LI, G. \& P.W. FRITSCH. 2018. A taxonomic revision of taxa in Styrax series Cyrta (Styracaceae) with valvate corollas. J. Bot. Res. Inst. Texas 12:579-641. Stable URL: https://www.jstor.org/stable/26549488

Xu, W.-B., P. YANG, Y.-S. HuANG, R. ZHANG, \& M. TANG. In press. Styrax hwangiae (Styracaceae), a new species endemic to limestone areas of Guangxi, China. Phytotaxa.

Zhou, H., W. YANG, M. LI, \& X.-L. Yu. 2015. Styrax rhytidocarpus (Styracaceae), a new species from Hunan, China. Phytotaxa 230(1):87-91. doi:10.11646/phytotaxa.230.1.9 